\title{
INVESTIGATION OF THE DYNAMIC LOAD UNIT TO HYDRAULIC WORKSTATION
}

\author{
Edgars Repsa, Eriks Kronbergs \\ Latvia University of Life Sciences and Technologies, Latvia \\ edgars.repsa@1lu.lv, eriks.kronbergs@1lu.lv
}

\begin{abstract}
Hydraulic systems of agricultural, forest and road construction machinery are affected by different negative and positive loads. In order to mediate the dynamic properties of the hydraulic system with positive and negative forces, a dynamic load unit is used as an attachment to the hydraulic workstation. Heavy vertical load unit $(80 \mathrm{~kg})$ is suspended by an industrial type hydraulic cylinder CD70H25/16+DBDS6G1X/50. The Festo Didactic hydraulic Training Station lets to create the necessary hydraulic control circuit, which is presented. For negative load forces, when the directional valve shifts to load lowering, overrunning load forces occur. Then the actuator moves faster than the pump flow can fill it. Incorporating a pressure control valve called a counterbalance valve is a better way to control running-away loads. The hydraulic control system was developed for adjustment the dynamic load unit with the hydraulic work station. For the hydraulic cylinder piston diameter $25 \mathrm{~mm}$, rod diameter $16 \mathrm{~mm}$ and load unit $80 \mathrm{~kg}$ the counterbalance valve calculated necessary pressure setting is 27 bar. Physical simulation with the load unit lifting and lowering was realized experimentally. For pressure measurements in pressure and return lines a pressure sensor SCPT-600 was used. Pressure was registered during the load unit lifting and lowering cycles with a service and diagnostic instrument "Service Master" and a portable computer. The obtained pressure diagrams during simulation show that the counterbalance calculated pressure setting 27 bar lets prevent overrunning load forces, when the actuator moves faster than the flow can fill it. Dynamic load unit is equipped with load springs at the end of load lowering, therefore, the linear characteristic of pressure change is observed. At the hydraulic cylinder, there is a throttle screw, by means of which the top end position cushioning of the piston can be set. Thus, the stroke speed of the hydraulic cylinder in the top end position is decelerated and the cylinder moves into the top end position in a dampened form.
\end{abstract}

Keywords: hydraulic systems, dynamic load simulation.

\section{Introduction}

Education of hydraulic fluid power systems is important for future engineers, working with agricultural, forest and road construction machinery. These mobile machines are affected by important negative and positive loads on hydraulic cylinders of work equipment. The extension and retraction speeds of hydraulic cylinders are necessary to manage [1] by controlling the inlet or exit-oil flow rates. The cushioning arrangement might be necessary to reduce the piston speed to a limiting value before reaching its end position. It is stated [2-4] that cushioning time and peak pressure can be used to evaluate the cushioning process. The previous hydraulic laboratory workstation - the Festo Didactic hydraulic Training Station did not provide performance studies of hydraulic cylinders under heavy dynamic loads. Recommended by Rexroth Bosch Group Dynamic the load unit to Hydraulic Training System was provided. There is possibility to experimentally investigate the cushioning process at the end of load lifting. The main problem usually is lowering the load. It is called as overrunning or negative load, when load moves the actuator piston too fast during the lowering process. By the dynamic load unit then the hydraulic cylinder is extended. The impact may occur at the end of the uncontrolled load lowering and the cavitation process can happen at the cylinder rod - less cavity which is connected to the pump. When the double-acting hydraulic cylinder extends below its load weight, the amount of fluid required on the piston side of the cylinder may exceed the amount of fluid delivered by the pump. If this happens, a vacuum is created on the piston side of the hydraulic cylinder and vapour formation occurs, which can be a cause of cavitation. The counterbalance valves are recommended $[5 ; 6]$ to ensure smooth motion of loads that are caused by an external, unidirectional force. This force is commonly caused by gravity. When a counterbalance valve is installed, the pressure in the load side of the actuator is always sustained whether the load is being lifted or lowered. The other studies indicate $[7 ; 8]$ that a counterbalance valves negatively affect the dynamical behaviour of most of the hydraulic systems in which they are utilized, and they introduce additional energy consumption. Therefore, only experimental studies may allow the effectiveness of the hydraulic cylinder braking to be evaluated. The aim of the present investigation is to adjust the dynamic load unit with the hydraulic control system on the hydraulic workstation. For this purpose the necessary hydraulic control system was developed and physical simulation with the load unit lifting and lowering was realized experimentally. 


\section{Materials and methods}

For experimental investigation the Festo Didactic Hydraulic Training Station with a dynamic load unit was used. Components can be found in Fig. 1.

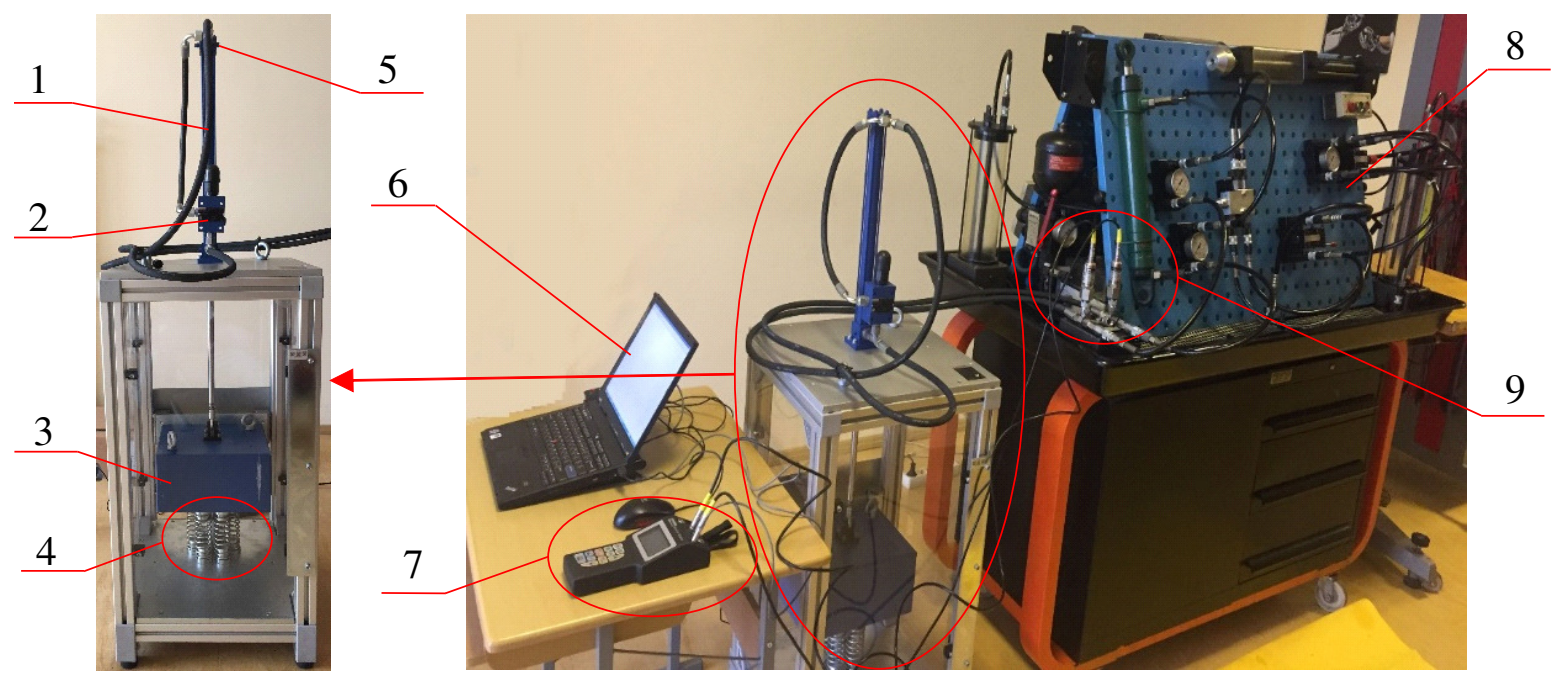

Fig. 1. Hydraulic workstation of experiments: 1 - hydraulic cylinder; 2 - pressure limiting valve;

3 - load weight; 4 - dampening buffer; 5 - throttle screw for end position cushion; 6 - computer;

7 - Service Master; 8 - Festo Didactic hydraulic Training Station; 9 - pressure sensors

During the experiments hydraulic pressure measurements were performed. For the load unit activation equipped the Festo Didactic hydraulic Training Station was used. Pressure was measured with calibrated pressure sensors (SCPT-600-02-02) and for data recording the service and diagnostic instrument "Service Master" SCM-360 connected to computer was used. Heavy vertical load unit ( $80 \mathrm{~kg}$ ), which is suspended by an industrial type hydraulic cylinder CD70H25/16+DBDS6G1X/50, was used for investigation of the dynamic properties of the hydraulic system with positive and negative mass forces.

For dynamic load unit adjustment with the Festo Didactic hydraulic Training Station a developed hydraulic diagram with the counterbalance valve is shown in Fig. 2.

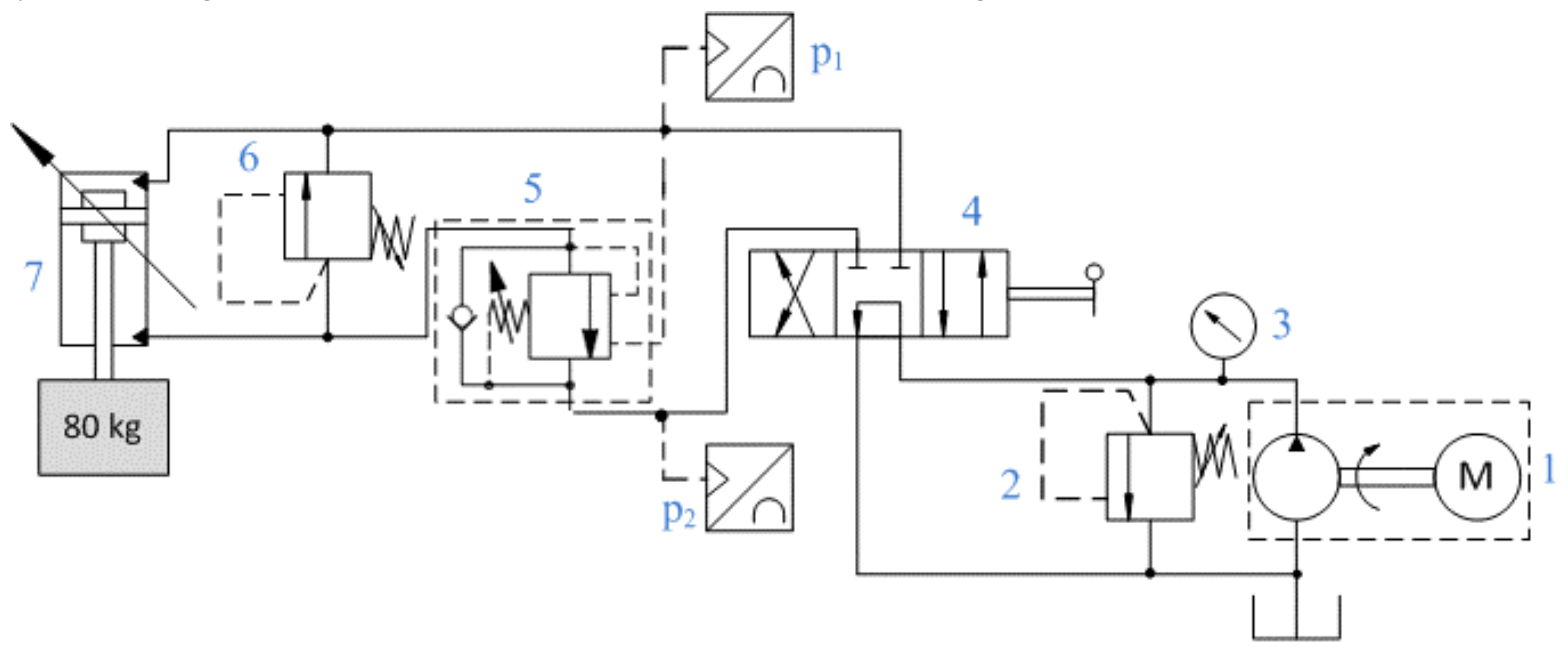

Fig. 2. Hydraulic scheme: 1 - hydraulic pump unit; 2 - safety valves; 3 - manometer; 4 - direction valve; 5 - counterbalance valve; 6 - pressure limiting valve; 7 - load unit; $\mathrm{p}_{1}, \mathrm{p}_{2}$ - pressure sensors

Fig. 2 shows the hydraulic scheme with a counterbalance valve 5, it comprises a fixed displacement pump, which is driven by an electric motor', a 4/3 way manually operated directional control valve, a differential hydraulic cylinder equipped with load weight, a dampening buffer, a pressure limiting valve and a throttle screw for the end position cushion. Pressure limiting valve 
restricts the attainment of too high pressure values that may be caused by the difference between the cylinder piston and the rod areas. Pressure sensors $\mathrm{p}_{1}$ and $\mathrm{p}_{2}$ for pressure measurements was used.

The calculated hydraulic cylinder: bore area $A_{1}=4.91 \cdot 10^{-4} \mathrm{~m}^{2}$; rod side annular area $A_{2}=2.9 \cdot 10^{-4} \mathrm{~m}^{2}$; rod area $A_{3}=2.01 \cdot 10^{-4} \mathrm{~m}^{2}$; the cylinder ratio $\varphi=4.91 \cdot 10^{-4} / 2.90 \cdot 10^{-4}=1.69$. According to the cylinder ratio 1.69 , the safety valve connected to the rod side will operate at 100 bar, if the pressure in the piston side is -59.2 bar. For the load unit $80 \mathrm{~kg}$ the calculated required pressure in the rod side of the cylinder is 27 bar (ignoring the friction force). The task of the experiments was to investigate the cylinder end cushioning effect depending on throttle regulation and evaluate the counterbalance valve effect during experiments with the heavy vertical load unit. For comparison purposes, the scheme in Fig. 2 was also operated without a counterbalance valve.

\section{Results and discussion}

During the experiments pressure values for different cylinder end position cushioning regulations were recorded. The obtained results are shown in Fig. 3.

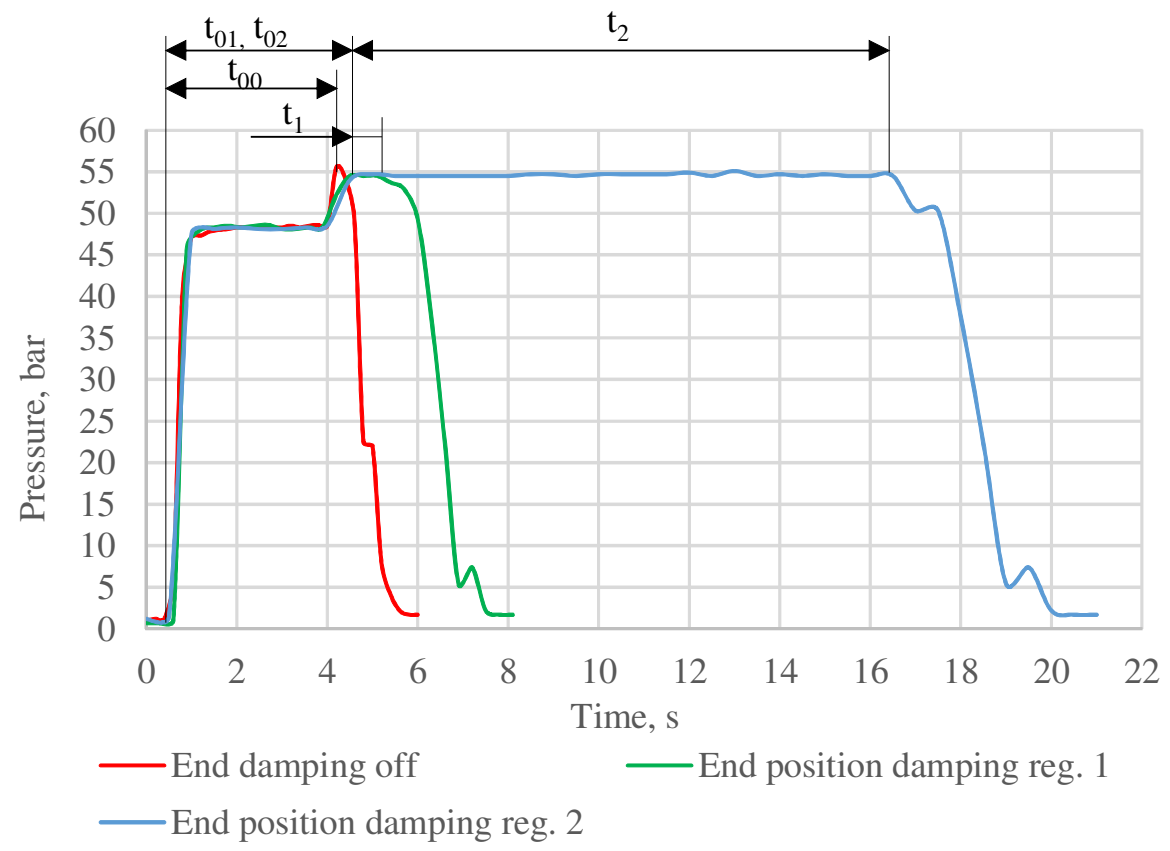

\section{Fig. 3. Cylinder end position cushioning (damping) pressure}

In Fig. 3 are compared pressure values for three different cylinder end position cushioning regulations. Pressure $\mathrm{p}_{2}$ was registered during the load unit lifting. Time interval $t_{00}$ shows the running pressure values for load weight in distance from start to end position without cylinder end position cushioning. Time interval $t_{01}$ and $t_{02}$ show the running pressure values with end cushioning regulation 1 and 2. Time $t_{1}$ and $t_{2}$ show the end cushioning interval. The obtained results show that the pressure $\mathrm{p}_{2}$ rapidly increases to the necessary working pressure 48 bar after switching on the direction valve. When the end cushioning throttle was completely open at the end of the stroke, a rapid increase in pressure up to the safety valve regulation 54 bar was observed. Using the end throttle different regulations, the cylinder piston reaches its end position accordingly to times $t_{1}$ and $t_{2}$. As the throttle closes, the cushioning time increases correspondingly. The safety valve at the pump is open in all cushioning situations.

In Fig. 4 are shown pressure diagrams without the counterbalance valve. Positions for the pressure $\mathrm{p}_{1}$ sensor and $\mathrm{p}_{2}$ sensor are shown in Fig. 2. Pressure $\mathrm{p}_{1}$ is measured at the piston side and $\mathrm{p}_{2}$ at the rod side of the hydraulic cylinder. Stage I shows the load unit lifting. In this stage, the pressure $\mathrm{p}_{2}$ rapidly increases to the work pressure 48 bar and in the end of stroke the pressure values reach the safety valve regulation 54 bar. Pressure $\mathrm{p}_{1}$ is output pressure that increases as a result of the flow resistance up to 8 bar. Load unit lowering is shown in stages II and IV. Stage II shows the lowering distance from start to the dampening buffer. In this interval the pressure $\mathrm{p}_{2}$ decreases, but the pressure $\mathrm{p}_{1}$ can 
reach negative values -0.3 bar. When the load unit stops at the dampening buffer, then in stage III the pressure $\mathrm{p}_{1}$ increases. Stages II and IV show the load unit lowering process.

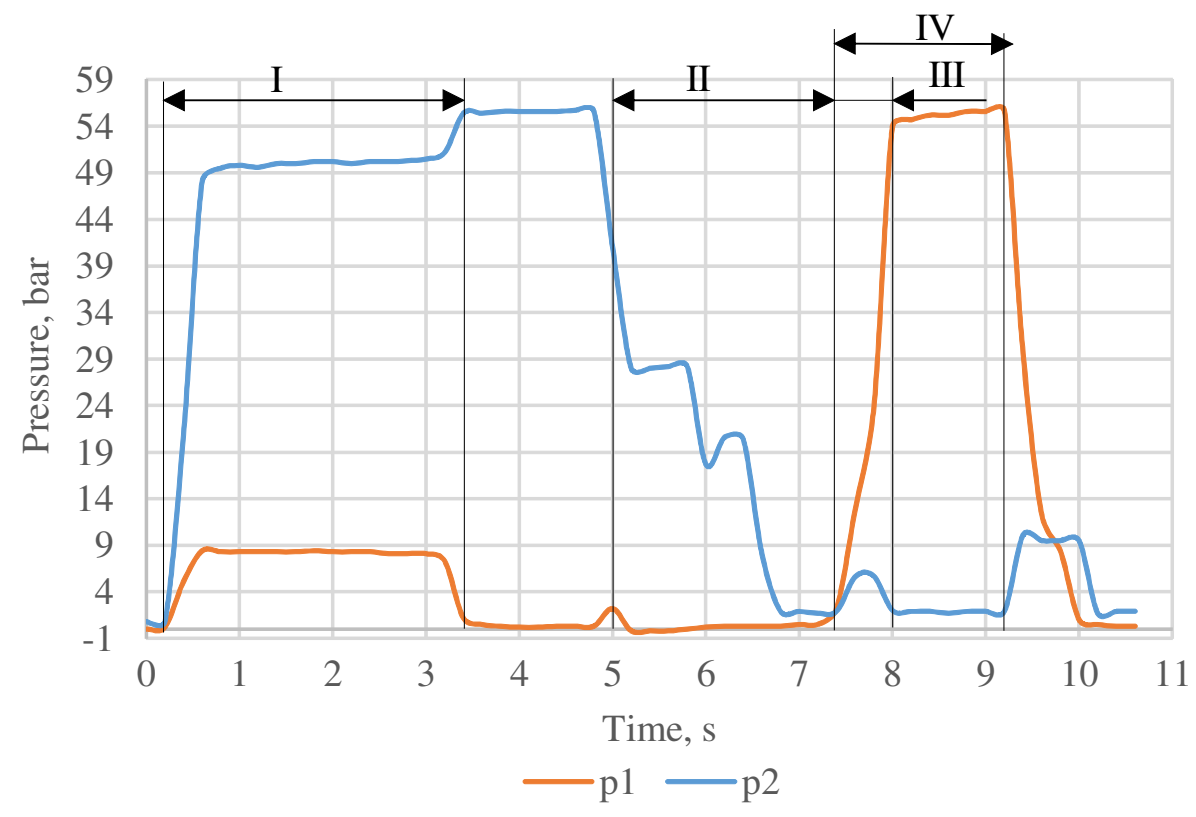

Fig. 4. Pressure diagrams without counterbalance valve

During the load unit lowering the pressure in the piston side decreases to the value -0.3 bar. This may be the cause of cavitation on the piston side. Therefore, operating the circuit without a counterbalance valve is not recommended.

Fig. 5 shows pressure diagrams with the counterbalance valve. Load unit lifting and lowering cycle was divided like in the previous Fig. 4.

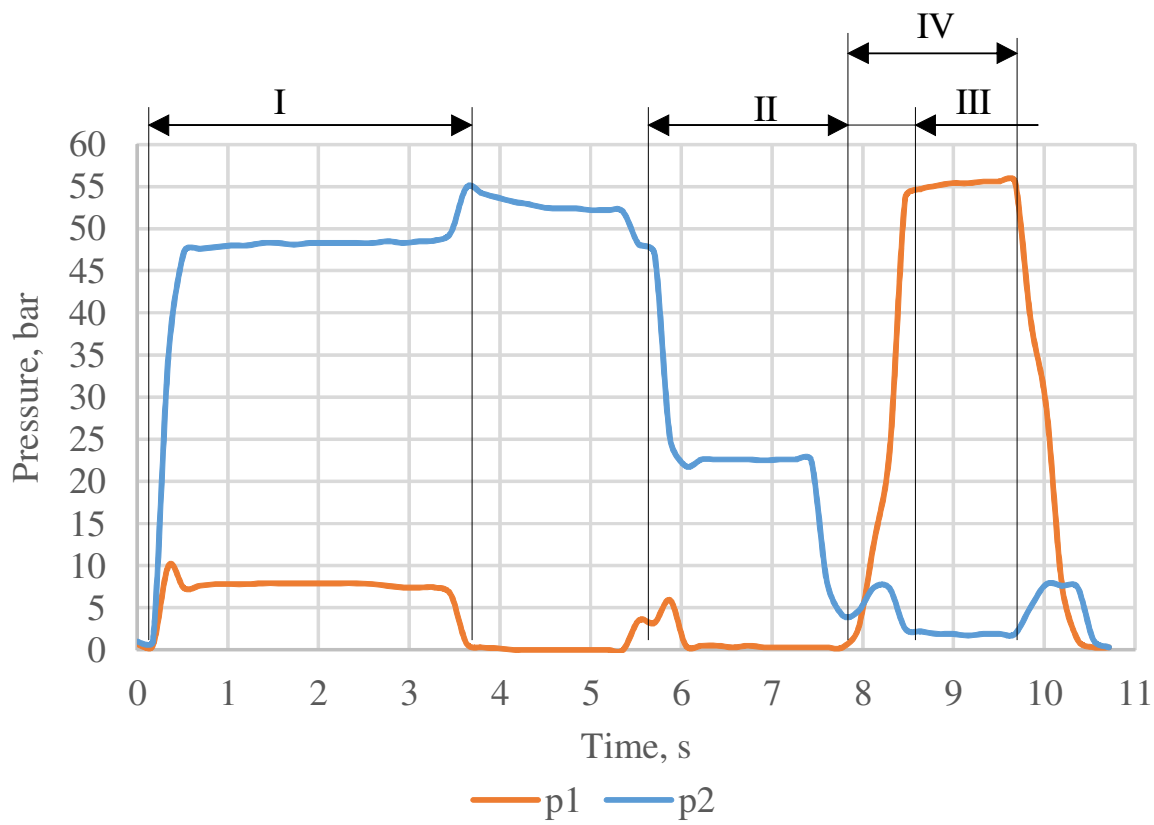

Fig. 5. Pressure diagrams with counterbalance valve

Important difference can be observed in stage II. During the load unit lowering the pressure $\mathrm{p}_{1}$ did not reach negative values and at the piston side it reaches the value 0.4 bar. In the lowering cycle, the pressure in the rod side is 23 bar, which is $14 \%$ different from the calculated value of 27 bar, which can be explained by the effect of the frictional force in the hydraulic cylinder. Adjustment of the dynamic load unit to the Festo Didactic hydraulic Training Station lets introduce engineering students 
with negative and positive loads on hydraulic cylinders of work equipment. The use of counterbalance valves in the hydraulic circuit for lowering heavy loads prevents vacuum in the hydraulic cylinder and allows to avoid cavitation. The cushioning at the end positions of the piston in the hydraulic cylinder prevents the impact against the cylinder cups.

\section{Conclusions}

1. For the dynamic load unit adjustment with the Festo Didactic hydraulic Training Station a hydraulic circuit with included counterbalance valve was developed.

2. Cushioning time increases corresponding to the throttle closing at the end position of the hydraulic cylinder. The safety valve at the pump is open in all cushioning situations.

3. During load unit lowering the pressure in the piston side decreases to the value -0.3 bar. This may be the cause of cavitation on the piston side. Therefore, operating the circuit without a counterbalance valve is not recommended.

4. During load unit lowering the pressure $\mathrm{p}_{1}$ did not reach negative values and at the piston side it reaches the value 0.4 bar.

5. In the lowering cycle, the pressure in the rod side is 23 bar, which is $14 \%$ different from the calculated value of 27 bar, which can be explained by the effect of the frictional force in the hydraulic cylinder.

6. Adjustment of the dynamic load unit to the Festo Didactic hydraulic Training Station lets introduce engineering students with negative and positive loads on hydraulic cylinders of work equipment.

7. The use of counterbalance valves in the hydraulic circuit for lowering heavy loads prevents vacuum in the hydraulic cylinder and allows to avoid cavitation. Introduction of additional energy consumption may be avoided, as for constant dynamic load unit the necessary working pressure of the counterbalance valve can be calculated and adjusted precisely.

8. Cushioning at the end positions of the piston in the hydraulic cylinder prevents the impact against the cylinder cups.

\section{References}

[1] Rabie M.G. Fluid power engineering. New York: McGraw-Hill Companies, 2009. 420 p.

[2] Chena X., Chena F., Zhou J. etc. Cushioning structure optimization of excavator arm cylinder. Automation in Construction, vol. 53, 2015, pp. 120-130.

[3] Komsta J., Oijen N., Antoszkiewicz P. Integral sliding mode compensator for load pressure control of die-cushion cylinder drive. Control Engineering Practice, vol. 21, 2013, pp. 708-718.

[4] Lai Q., Liang L., Li J., Wu S., and Liu J. Modeling and Analysis on Cushion Characteristics of Fast and High-Flow-Rate Hydraulic Cylinder. Mathematical Problems in Engineering, vol. 2016, 2016, pp. 1-17.

[5] Akers A., Gassman M. and Smith R. Hydraulic power system analysis. Boca Raton, London, New York: Taylor \& Francis Group, 2006, 358 p.

[6] Durfee W., Sun Z and Van de Ven J. Fluid Power System Dynamics. Department of Mechanical Engineering University of Minnesota, Minneapolis, USA, 2015, 54 p.

[7] Ritelli G.F., Vacca A. Energetic and dynamic impact of counterbalance valves in fluid power machines. Energy Conversion and Management. 76, 2013, pp. 701-711.

[8] Yao Y., Zhou H., Chen Y., Yang H. Stability Analysis of a Pilot Operated Counterbalance Valve for a Big Flow Rate. Proceedings of the ASME/BATH 2014 Symposium on Fluid Power \& Motion Control FPMC2014, September 10-12, Bath, United Kingdom, pp. 1-12. 